\title{
Locas de la limpieza y técnicas industriosas del cuerpo en una villa obrera
}

\author{
Bárbara Galarza \\ UNICEN, Olavarría, Argentina \\ Correo electrónico: barbaragalarza@gmail.com
}

Recibido

noviembre de 2018

Aceptado

mayo de 2019

doi: $10.34096 /$ cas.i50.5375

\section{Resumen}

A pesar de su presencia en la vida cotidiana, la producción cultural asociada a la figura vernacular de la loca de la limpieza es un fenómeno escasamente estudiado en América Latina. Con el objetivo de contribuir a esta vacancia, abordo con un enfoque etnográfico el modo en que las mujeres de una villa obrera industrial se adiestran en técnicas corporales para convertirse en expertas en limpieza. El trabajo se divide en cuatro partes. En primer lugar, defino la instrucción en estas técnicas corporales como una práctica encarnada que aparece asociada al malestar. En segundo lugar, describo ciertas instancias en las que las mujeres aprenden a limpiar. Tercero, demuestro que la educación en la limpieza se considera satisfactoriamente adquirida cuando, luego del aprendizaje táctil, olfativo y visual, las mujeres adquieren disposiciones que les permiten sentir la mugre en el cuerpo. Finalmente, vinculo esta identidad al sistema productivo en el que es vivida como una praxis social.

\section{Crazy cleaning ladies and industrious bodily techniques in a wor- king class village}

\footnotetext{
Abstract

Despite its presence in everyday life, the cultural production associated with the vernacular figure of loca de la limpieza -the crazy cleaning lady- is a scarcely studied phenomenon in Latin America. In an attempt to contribute to this vacancy, I research with an ethnographic approach the way in which industrial working class women are trained in body techniques to become cleaning experts. The work is divided in three parts. Firstly, I define the training in these bodily techniques as an embodied practice associated with distress. Secondly, I describe some of the instances in which women learn cleaning up methods. Thirdly, I demonstrate that learning to clean is considered accomplished when women acquire tactile, olfactory and visually informed dispositions that allow them to feel dirt in their own bodies. Finally, I link loca de la limpieza identity to the productive system in which it is lived as social praxis.
}

\section{Palabras clave}

Técnicas del cuerpo; Técnicas industriosas; Locura vernacular; Locas de la limpieza; Villa obrera

\section{Key words}

Bodily techniques; Industrious techniques; Vernacular distress; Crazy cleaning ladies; Working class village 


\section{As Loucas da limpeza e as técnicas corporais diligentes numa cida- de de trabalhadores}

\section{Resumo}

Palavras-chave

Técnicas corporais; Técnicas industriais;

Loucura vernácula; Louca da Limpeza; Cidade de proletariado
1. Utilizo cursivas para ponderar categorías nativas y/o analíticas y las comillas para citas textuales.
Apesar da sua presença no quotidiano, a produção cultural associada à figura vernacular da faxineira é um fenómeno pouco estudado na América Latina. Este artigo é uma tentativa de contribuir com essa ausência através de uma abordagem etnográfica, abordando a maneira pela qual as mulheres de uma cidade de trabalhadores industriais são treinadas em técnicas corporais para se tornarem especialistas em limpeza. $\mathrm{O}$ trabalho está dividido em três. Em primeiro lugar, defino a instrução dessas técnicas corporais como uma prática incorporada que aparece associada ao desconforto. Em segundo lugar, descrevo certos casos em que as mulheres aprendem a limpar. Em terceiro lugar, demonstro que a educação em limpeza é considerada satisfatoriamente adquirida quando, após o aprendizado palpável, olfativo e visual, as mulheres adquirem disposições que lhes permitem sentir a sujeira no corpo. Por fim, vinculo essa identidade ao sistema produtivo em que ela é vivida como uma praxis social.

Convertir su corazón en un lugar acogedor suponía un trabajo mentalmente escurridizo. A veces implicaba una limpieza, reorganizar las cosas. Tenía que quitar el polvo [...] Resultaba todo tan tedioso, pero se esmeraba en ello hasta que consiguió meter dentro a toda la maldita familia.

(Erdrich, 2016, p. 245)

\section{Introducción}

Este trabajo tiene por objetivo caracterizar la locura de la limpieza ${ }^{1}$ como una técnica corporal de expertización en un tipo de trabajo no asalariado que se aprende a hacer sin instrucción formalizada y que resulta de gran importancia para el desarrollo capitalista en la región centro-bonaerense en las primeras décadas del siglo xxi. El argumento antropológico que con la descripción etnográfica intento sustentar es que la producción de sentido nativa asociada a la loca de la limpieza provee un marco simbólico que educa en tareas productivo-reproductivas domésticas. Como estas tareas son "naturalmente" realizadas por mujeres que "enloquecen" al realizarlas, el análisis se centra en la objetivación de su dimensión vivencial. El supuesto que lo guía es que el valor de uso no reconocido que tienen estas prácticas para la producción industrial del cemento es el motor cultural de su praxis vernacular.

En la región centro-bonaerense, las personas suelen usar la palabra "trabajo" para referirse a labores industriales y el término "hacer las cosas de la casa" para referirse a las labores domésticas. Tal distinción se constituye sobre la base económica de la sociedad salarial (Castel, 1997), que produce, en el capitalismo tardío, la plusvalía industrial (Marx, 2011). Parte de su organización social se construye alrededor de diferentes tipos de trabajadores: aquellos que perciben salarios en blanco y aquellos cuya remuneración es directamente inexistente o en negro. La ausencia de salario dificulta al trabajador el acceso, entre otras cosas, a la previsión social. La salarización resulta, por tanto, un elemento clave en la organización social de los cuerpos que cooperativamente metabolizan su energía vital para producir capital industrial. 
La ausencia de retribución salarial a las amas de casa por el trabajo que "naturalmente" realizan con cuidado (Tronto, 2015) es un tema tanto de la agenda teórica feminista contemporánea (Fraser, 1997; Federici, 2018) como de la política pública nacional desde los años 2000. Atendiendo al problema social de la población que, habiendo trabajado todas su vidas sin remuneración o en empleos informales, en su vejez se encuentra excluida del derecho a una jubilación, en el año 2004, el gobierno de Néstor Kirchner estableció la llamada "jubilación sin aportes", popularmente conocida como la jubilación del ama de casa. Gracias a ella, se jubilaron 2.700 .000 personas, el 87\% de las cuales fueron mujeres.

El enfoque antropológico construido alrededor de la perspectiva nativa del ama de casa que aquí desarrollo busca describir y analizar tanto las tareas y acciones físicas del trabajo concreto de los actores como de la constelación simbólica encarnada en su propio cuerpo al aprender a realizarlas.

Buscando comprender el modo en que se transmiten técnicas industriosas del cuerpo entre mujeres de una villa obrera procedo de la siguiente manera. En primer término, conceptualizo las técnicas del cuerpo de la loca de la limpieza. A continuación, sitúo el problema de investigación en el contexto de Villa Caliza y su organización social como sistema de fábrica con villa obrera. Luego, considero la locura vernacular como un proceso sociocultural más que como un problema psicológico, situándola como práctica encarnada. Finalmente, describo instancias en las que las mujeres aprenden a limpiar desde niñas, y las examino como técnicas del cuerpo que generan disposiciones y una hexis industriosa por la que se siente la mugre en todo el cuerpo.

El corpus documental que produjo el material de análisis de esta investigación es resultado de un trabajo de campo realizado en varias etapas entre 2012 y 2017, que combinó entrevistas en profundidad, abiertas y semiestructuradas y registros de observación, con 20 mujeres amas de casa de entre 26 y 65 años, casadas, en pareja y/o separadas de trabajadores calificados y no calificados de canteras y fábricas de una villa obrera en la región centro-bonaerense. ${ }^{2}$

\section{Técnicas corporales, cuerpo social y hexis corporal}

En la antropología, el interés por las prácticas nativas que involucran al cuerpo y que son universalmente comunes a todos los pueblos y particulares a cada uno de ellos en su singularidad fue originalmente explorado por Marcel Mauss. Entre sus preocupaciones se encontraban las técnicas y movimientos corporales, la expresión imperativa de sentimientos y las nociones de persona y yo (Mauss, 1979). Al sostener que "lo que hace falta es un triple punto de vista, el del hombre total" (Mauss, 1979, p. 340), el investigador promovía el holismo como aproximación analítica. El énfasis de su teoría está puesto en comprender la naturaleza social de la transmisión de las técnicas. En Sociología y Antropología, se ofrece una contextualización de las técnicas corporales en términos de "tecnologías", y se las clasifica en tres grupos: las técnicas generales de usos generales, que se "caracterizan por la presencia de un instrumento" (Mauss, 1979, p. 52); las técnicas generales de usos especiales o industrias generales de usos especiales, que se definen por la especialización del trabajo en cada sociedad; ${ }^{3}$ y las industrias especializadas de usos especiales, que satisfacen el "consumo" en las sociedades industriales.

El estudio minucioso de las técnicas corporales que emprendió Mauss fue simultáneo a la propagación del taylorismo como sistema organizacional fabril, caracterizado por sistematizar y segmentar las tareas y el conjunto de gestos en que se divide el proceso productivo industrial. Su clasificación da cuenta de las técnicas corporales propias de
2. En 2015, los ingresos de estas unidades domésticas oscilaban entre los 20.000 y 30.000 pesos mensuales (1.500 y 2.200 dólares, respectivamente).
3. Esta especialización productiva se asocia a la aparición de lo que Richard Sennett (2009) Ilamó el trabajo artesanal (herrería, alfarería, carpintería, etcétera). 
4. Mindful body, en inglés. 5. En ingles en el original. La traducción es mía. los escenarios del capitalismo central. La especialización productiva y la industrialización suponen el dominio pleno sobre la naturaleza y la capacidad técnica de valerse de herramientas y de destrezas físicas para transformarla. El cuerpo constituye así el principal medio técnico de la humanidad en un sentido productivo amplio, que excede la fabricación de cosas. Mauss se interesa especialmente por aquellas actitudes y posturas que, de tan naturalizadas por la tradición son, para los miembros de una cultura, el modo "natural" de hacer y poner el cuerpo. Ejercita así el extrañamiento de las acciones más "sencillas", tales como caminar, correr, nadar, hablar, besar, conversar y cortejar. El presente trabajo extiende esa capacidad de extrañamiento a las destrezas en la limpieza que las mujeres se esfuerzan por transmitir unas a las otras en interacciones que podrían considerarse parte de una educación técnica informalmente institucionalizada.

Cuando se les pregunta por la limpieza, las mujeres responden hablando de la locura. Limpiar las "vuelve locas", dicen. Resulta evidente, en el fenómeno de "la locura de la limpieza", que la interfaz entre lo corpóreo y lo mental es clave. El antropólogo Michael Lambek identifica esta interfaz como siendo parte de "una larga conversación" en el pensamiento (no solo occidental) a la que la antropología podría aportar etnografías que se pregunten cuánto hay de mente en el cuerpo y cuánto hay de cuerpo en la mente (Lambek, 1998). De manera análoga, Nancy Scheper-Hughes y Margaret Lock (1987) propusieron ocuparse de la intersección entre cuerpo y mente en las experiencias del sufrimiento, la salud y la enfermedad. Para desandar esa oposición cartesiana llamaron "cuerpo mental" 4 al cuerpo individual en el que se juegan las "contradicciones sociales" y que funciona como "locus de la resistencia, la creatividad y la lucha personal y social" 5 (p. 31). Justamente, al abordar un fenómeno que se enuncia nativamente como locura de mujeres, surge el riesgo de producir una caricatura misógina que obstaculice la explicación del fenómeno con un sentido holístico, es decir, como siendo parte de una totalidad sociohistórica. Tal es la tendencia en aquellas perspectivas que producen una imagen folk, esto es, pintoresca, autocontenida y ahistórica de la locura. El paradigma del embodiment (Csordas, 2010) ha intentado superar las dicotomías clásicas de lo tradicional y de lo moderno y de lo físico y lo mental, factores que convergen en una propuesta de investigación que recupera el concepto de habitus de Pierre Bourdieu (1991). En este marco, el estudio de las técnicas corporales se complementa con el de los modos somáticos de atención entendidos como "modos culturalmente elaborados de prestar atención a, y con, el propio cuerpo, en entornos que incluyen la presencia corporizada de otros" (Csordas, 2010, p. 87). Este concepto resulta de gran operatividad etnográfica a la hora de registrar y describir la dimensión vivencial (encarnada y simbolizada) de la locura asociada a la limpieza como el proceso social de inscripción de una singular hexis corporal. La noción da cuenta de la inscripción procesual de la especialización productiva inconsciente en el propio cuerpo del actor, pues permite objetivar aquel elemento corporizado del habitus que constituye una "disposición permanente, duradera, de mantenerse, de hablar, de caminar y, por ello, de sentir y de pensar" (Bourdieu, 1991, p. 119).

La loca de la limpieza es un término nativo que los trabajadores utilizan para hablar de las mujeres de la villa obrera: esposas, madres, hermanas, tías, cuñadas, etcétera. La bibliografía especializada identificaría a esta figura con una construcción lega, no-profesional, folk o vernacular, que la diferencian de los diagnósticos profesionales biomédicos o psiquiátricos, que asociarían sus síntomas a trastornos de ansiedad o desordenes obsesivo-compulsivos, de acuerdo con un lenguaje típicamente psi. $\mathrm{Al}$ focalizar mis preguntas en la dimensión sociocultural más que en la psicológica, centro la indagación en la producción de sentido asociada a las prácticas de limpieza en los repertorios nativos de los actores. 


\section{Villa Caliza y el sistema de fábrica con villa obrera}

Villa Caliza ${ }^{6}$ es un pueblo de 4000 habitantes, que se dedica, desde fines del siglo xix, a la extracción minera y, desde la segunda década del siglo $\mathrm{xx}$, a la producción industrial de cemento. Su producción abastece el 50\% del mercado nacional, lo que la constituye en el principal generador de trabajo en la ciudad (tanto directo como indirecto) y en uno de los principales proveedores mineros de la industria de la construcción de Argentina, dado que abastece el $20 \%$ de la obra pública nacional.

El paisaje social de Villa Caliza es el de una sociedad industrial, conformada por trabajadores de la minería, obreros, camioneros, mecánicos, choferes de transporte privado (para llevar a los obreros a las canteras y a las fábricas), maestras, comerciantes de verdulería, carnicería, pollería, almacenes, panadería, corralón, zapatería, quioscos, locales de ropa, empleadas públicas municipales, policías y amas de casa.

La identidad del pueblo se construye con sentidos positivos y negativos que se tejen alrededor del cemento. En un libro escrito y editado por dos maestras de escuela primaria donde se recoge la historia de Villa Caliza, se hace mención al "problema de la ceniza", y se explicita que "el cemento que sale de las chimeneas de la fábrica nos vuelve locos", y que se trata de un "inconveniente que ocasiona la fábrica de cemento desde siempre, desconsideradamente" (Zito y Coumeig, s/f, p. 252). En esta sección, un vecino de la localidad, comerciante de 58 años, rememora como "uno de los momentos más alegres de la historia del pueblo, cuando pusieron el filtro" (Zito y Coumeig, s/f, p. 245). El "problema de la ceniza" implica, para los vecinos, una gran contradicción pues, por un lado, si hay ceniza, eso quiere decir que la "fábrica está funcionando y hay trabajo pero, por el otro, también que vivimos llenos de mugre todo el día” (Entrevista, Hugo, empleado de fábrica, 52 años, agosto 2105). La chimenea es la principal pero no la única fuente de polvo y tierra constantes. La explotación a cielo abierto en canteras de las que se extrae la caliza (materia prima del cemento) nutre asimismo la constante nube polvorienta que se cuela a diario en las casas (Imagen 1).

La división sexual del trabajo de los villacalicenses comienza a configurarse desde una temprana edad, en los ámbitos educativos y domésticos en que se socializan. Los varones son instruidos como mano de obra calificada o semicalificada en la Escuela Técnica Industrial No 1 "Luciano Fortabat" de la ciudad de Olavarría, cabeza administrativa

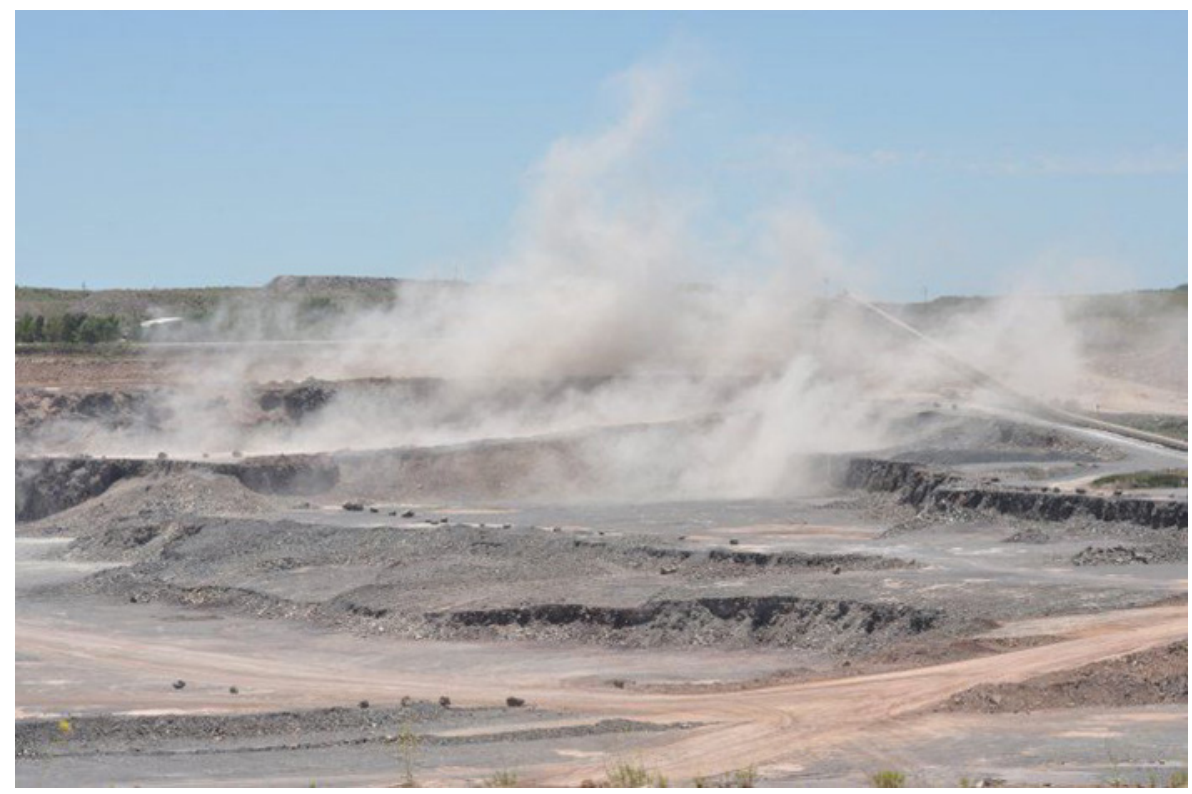

6. Este nombre es ficticio.

Imagen 1: Cantera dedicada a la extracción de la caliza, 2015.

Fuente: Imagen extraída del portal de noticias Infoeme, 07/05/2015, titulada "Día de la minería: Olavarría produce el 50\% del cemento del país". $s$ 
7. La empresa Fortabat, principal productora cementera argentina, entre las décadas de 1926 y 2005 , lleva el nombre de su fundador: don Luciano Fortabat.

8. Cabe señalar que esta situación cambió con la muerte de don Alfredo, en 1976, y la venta de la cementera Loma Negra a la empresa brasileña Camargo Correa en 2005, que se convirtió en su socia mayoritaria. En 2017, Loma Negra debutó en Wall Street con el objetivo de adquirir liquidez ofreciendo al mercado financiero internacional un conjunto de acciones de bolsa.

9. La villa obrera se diferencia de la llamada villa miseria por poseer mayores condiciones de empleo formal y una más alta provisión de consumos colectivos urbanos (vivienda, luz, agua, gas, etcétera).

10. Cabe señalar que la mayoría de las mujeres empleadas en la fábrica y en las canteras lo hacen como personal administrativo y/o de limpieza.

11. Desde la década de 1970, Olavarría cuenta con una facultad de Ingeniería. del partido bonaerense en que se encuentra Villa Caliza. Para acompañar el desarrollo cementero de la región, en un momento de gran expansión de esta rama productiva, don Alfredo Fortabat donó en 1963 una de sus propiedades para establecer la escuela. Esta institución educativa, a la que asisten casi exclusivamente varones, se ubicaba dentro de un sistema de "ayudas" y "regalos" en forma de becas y dinero que "el tío Fortabat" - como era llamado irónicamente por algunos trabajadores- gestionaba para su gran "familia" proletaria local.

En Fábrica y villa obrera: historia social y antropología de los obreros del cemento, Federico Neiburg analiza el sistema de dominación por el que se estructuran las relaciones de clase en términos personalistas, dentro y fuera de estas instalaciones industriales. Su estudio describe el proceso de transición de unas condiciones laborales propias del "capitalismo salvaje" durante los primeros años de la producción industrial del cemento, al de la llamada "comunidad organizada" o "el capitalismo humanizado", coincidente con las dos primeras presidencias de Juan Domingo Perón (Neiburg, 1989). Su principal característica es el involucramiento de los trabajadores en la "gran familia", "armónica" y "sin conflictos", de la empresa Fortabat, ${ }^{7}$ en la que todo conflicto (de clase) parece solucionarse en el marco de (imaginarios) dones que el generoso patrón da a sus empleados por fuera de la relación salarial (Neiburg, 1989)..$^{8}$

En esta magnífica etnografía de una villa obrera ${ }^{9}$ que describe la sociabilidad de los trabajadores de la industria cementera por más de tres generaciones, las mujeres son personajes secundarios invisibles. Al centrar el análisis en las relaciones del ámbito fabril, los problemas y los actores del ámbito doméstico, las amas de casa, parecerían no existir. “¿Dónde están las mujeres de este pueblo?”, le pregunté a un encargado de mantenimiento de planta una tarde de trabajo de campo. "En la casa limpiando, me respondió riéndose, limpiando como unas locas i¿dónde van a estar?!” (Registro de campo, Roberto, 55 años, julio 2014). ${ }^{10}$

La organización social de Villa Caliza es la de un sistema de fábrica con villa obrera (Leite Lopes, 1979) en el que todas las esferas de la vida productiva y reproductiva - la vivienda, los servicios públicos, la educación, el ocio, etc. - giran alrededor de la producción industrial. La organización sexual del trabajo en este sistema que se inscribe diferencialmente en el cuerpo de varones y mujeres podría sintetizarse del siguiente modo: una parte de los varones reciben instrucción formal en una institución técnica con el objetivo de acceder a un empleo asalariado en la industria. ${ }^{11}$ Una parte de las mujeres se educa en bachilleratos y escuelas comerciales con el propósito de acceder a puestos administrativos y/o continuar un nivel terciario de instrucción, por lo general, vinculado a la docencia. Formando parte de este grupo, se distingue otro mayor, que incluye a las maestras y administrativas: el del ama de casa. Teniendo en cuenta que no existe en Villa Caliza una escuela técnica doméstica para instruir al ama de casa, ¿cómo aprenden estas mujeres a serlo? ¿Cómo adquieren las disposiciones y destrezas del trabajo doméstico? En otras palabras: ¿cómo las niñas de clase obrera se convierten en locas de la limpieza de clase obrera? La figura vernacular de la loca de la limpieza llamó mi atención cuando hacía trabajo de campo sobre las prácticas profesionales y legas de tratamiento de la salud mental en la región centro-bonaerense. $\mathrm{Al}$ pedir a los actores que me la describieran, recurrentemente muchos hombres y mujeres la asociaban a una mujer de su propia familia, cuadra o barrio, e incluso a ellas mismas, cuya característica preponderante es la de un frenético comportamiento de pasarse el día limpiando. Estas descripciones nativas me hacían preguntar: ¿es la proliferación de locas de la limpieza un problema de salud mental subdiagnosticado medicamente pero sobrediagnosticado vernacularmente? ¿Cuál es la relación entre esta locura de la limpieza (vivenciada, reivindicada y resistida por las mujeres) y su función de reproducción en la villa obrera? 


\section{La loca de la limpieza}

Un típico día de esta mujer ${ }^{12}$ comienza al baldear la vereda con el sol apenas asomando y con la helada invernal aún cristalizada sobre la acera. Muchos rememoran cruzársela camino a la escuela cuando eran pequeños y preguntarse por qué "esta loca madruga y se pone a limpiar tan temprano si no tiene que ir a la escuela o a la fábrica", lugares a los que los niños y los hombres del pueblo concurren a diario. Además de realizar sus labores con obsesión, la loca de la limpieza se caracteriza por hacerlo con una apariencia personal desaliñada. Ella "anda siempre así nomás, con ropa de limpiar", sintetizan los entrevistados. Esta ropa, que suele ser cómoda (buzos y calzas), ostenta el uso de muchos años y múltiples manchas de cloro — adquiridas durante la ejecución de la limpieza - y sedimentadas manchas de comida — adquiridas durante las tareas vinculadas a la cocina-. Paradójicamente, tal apariencia sirve para denotar cuán limpitas son y cuán impecable tienen siempre su casa. Tal atributo se produce configurando una imagen personal que las distingue de otras mujeres, llamadas "conchudas, que se caracterizan por andar siempre arregladitas pero que no lavan un plato ni te cocinan un huevo frito", como me explicó un ama de casa de 40 años, de joggings, zapatillas y remera desteñida mientras barría la ceniza de la vereda y señalaba con el mentón la casa de "la maestra d'enfrente que no hace ni los mandados" (Registro de campo, Silvina, 45, ama de casa, abril 2015).

En algunos casos, la locura funciona como un valor positivo que indica el alto nivel de compromiso de la mujer en sus labores reproductivas. Pero llamativamente, en otros casos, en cambio, se la considera negativamente, como un indicador de exceso, que señala que aquella mujer que se la pasa todo el día sacando mugre está mal de la cabeza. En su descripción, los actores acompañan estas palabras con un guiño - que funciona como un diagnóstico nativo de chifladura-, ${ }^{13}$ que consiste en apoyar el dedo índice en la sien y alzar los ojos estirando exageradamente las cejas hacía arriba, en expresión de asombro, mientras enuncian las palabras "mal-de-la-cabeza".

Sus labores cotidianas típicas, además de baldear, consisten en hacer los mandados, cocinar, lavar los platos, dejar las rejillas ${ }^{14}$ remojándose en lavandina, repasar el baño para que quede en condiciones, ventilar la casa, pasarle un trapo al piso y refregar el polvo de las persianas con vinagre y esponja para raspar los cascarones de cemento pegado. También poner el lavarropa, colgar la ropa en el cordel del patio, entrarla, doblarla y guardarla. Gran parte de estos trabajos implican evaluar si la cantidad de polvo en el aire hace posible su ejecución. Por ejemplo, los días que hay mucha ceniza es mejor no ventilar. Pero si el día está lindo, hay sol y la fábrica no tira (ceniza), una aprovecha a abrir las ventanas y a sacar las almohadas y los acolchados al sol. Más tarde, si te das cuenta de que empezaron a tirar polvo, te tenés que apurar a entrar la ropa a la casa y cerrar todo. Más tarde, "salís a barrer y a echar un poco de agua, para sacar la mugre de la vereda" (Entrevista personal, Lorena, 29, ama de casa, abril 2015). Esta incesante danza que las chimeneas y las mujeres bailan a diario encuentra a las primeras arrojando los residuos de la mercancía cemento, y a las segundas baldeándolos, mientras maldicen esa acumulación que les estropea las plantas de las macetas y los malvones de los canteros del frente.

Para los chicos del barrio, la loca de la limpieza baldea a propósito para que ellos se refalen ${ }^{15}$ porque no le gusta que jueguen ahí. Al tener la vereda siempre mojada, impide la circulación sobre ella y previene el ensuciamiento del frente de su casa, así como la rotura de las plantas. Su locura no se reduce, de todas maneras, a este espacio exterior, sino que también se proyecta a las tareas que realiza en el interior. Se dice que puertas adentro esta mujer plancha como una loca pilones de ropa, y que sus hijos varones y su marido le llenan constantemente el canasto de la ropa. El blanqueamiento de la ropa es un valor tan positivo que, para lograrlo, se esmera practicando procedimientos que
12. Esta tipificación es una composición etnográfica construida a partir del testimonio de diversos actores. Considero la tipificación una útil herramienta heurística que permite condensar la descripción en relación con los propósitos del análisis. Véase Guber (2001, 2013).

13. Lunfardo para locura.

14. Paño que, humedecido, sirve para secar superficies mojadas o limpiar superficies sucias.

15. Lunfardo para resbalarse. 
16. Lunfardo para sucio o andra-

17. "Sacar el cuero" es una práctica nativa que consiste en hablar mal de una o más personas ausentes de una conversación.

18. Clifford Geertz liga lo vernacular al conocimiento local como "not just a place, time, class, and a variety of issues, but as to vernacular characterizations of what happens connected to vernacular imaginings of what can" (Geertz 1983, p. 215).

Imagen 2: Los villacalicenses en el día del Aniversario № 138 de fundación del pueblo. En el centro-fondo de la imagen se aprecia la fábrica. Foto tomada por la autora el 19-11-2017. otras mujeres le han transmitido inter e intrageneracionalmente. En ocasiones, es tanta la grasa que traen los varones de sus trabajos, además de la tierra que se les pega, que algunas mujeres con gesto de asco y cansancio explican que tienen que dejar "la ropa de Grafa en remojo con un poco de fluido para que afloje la mugre, si no, no la sacas con nada" (Entrevista personal, Susana, 47, ama de casa, enero 2017). Al contarme sus secretos, ciertas amas de casa confesaban utilizar productos fuertes, poco convencionales. Se sabe incluso de alguna que tiró acido para remover la grasa de los caños de la cocina, llegando a perforarlos. La grasa, dicen, las pone locas y la ven en todos lados: la cocina, la ropa, los vidrios, los pisos.

Toda mujer socializada en la villa obrera conoce a la loca de la limpieza desde su temprana infancia. Es como una especie de bruja en la que mágica e industriosamente toda niña del pueblo se convertirá. Existe una especie de imperativo social que empuja a las mujeres a esta conversión, pues las sanciones sociales de no hacerlo resultan indeseables. Es de conocimiento local que si una no tiene la casa en condiciones o si envía a sus hijos al colegio con la ropa "zaparrastrosa, ${ }^{16}$ sabés cómo te sacan el cuero ${ }^{17}$ en el pueblo, empiezan a decir que no sos muy loca de la limpieza que digamos y quedás como una mugrienta" (Registro de campo, Marta, 45, ama de casa, mayo 2015). Con tono de queja en la voz, muchas mujeres de Villa Caliza afirman ser una "de esas que se pasan todo el día limpiando".

\section{Limpiar y enloquecer como práctica encarnada}

Estudiar antropológicamente un problema implica indagar en la perspectiva nativa de los actores para proceder, en el análisis, a su extrañamiento. La capacidad de "descotidianizar" y producir el "extrañamiento de la conciencia práctica" conduce a descubrir "dimensiones de la realidad social que escapan a la percepción discursiva de los individuos que, no obstante, son fundamentales para la relación social” (Lins Ribeiro, 2011, p. 242). Algunas distinciones conceptuales resultan claves para comprender el enfoque metodológico de esta indagación. La noción de salud mental, perteneciente al repertorio técnico-profesional de la biomedicina, no ha sido una categoría utilizada por los actores de esta etnografía, por lo que no es tenida en cuenta. La noción de locura sí, en cambio, ha sido relevada siendo ampliamente utilizada en situaciones de la vida cotidiana. Es decir, mientras que salud mental es una categoría ausente de la perspectiva nativa indagada, la locura es una categoría emic utilizada por los actores para representar su propio malestar o el de otros. Partiendo de una definición amplia de lo vernacular, que lo entiende como aquel mundo heterogéneo, fragmentario, diseminado, aparentemente incoherente e informalmente institucionalizado de representaciones y prácticas (Geertz, 1983; ${ }^{18}$ Bowman y Valk, 2014), entiendo por locura vernacular

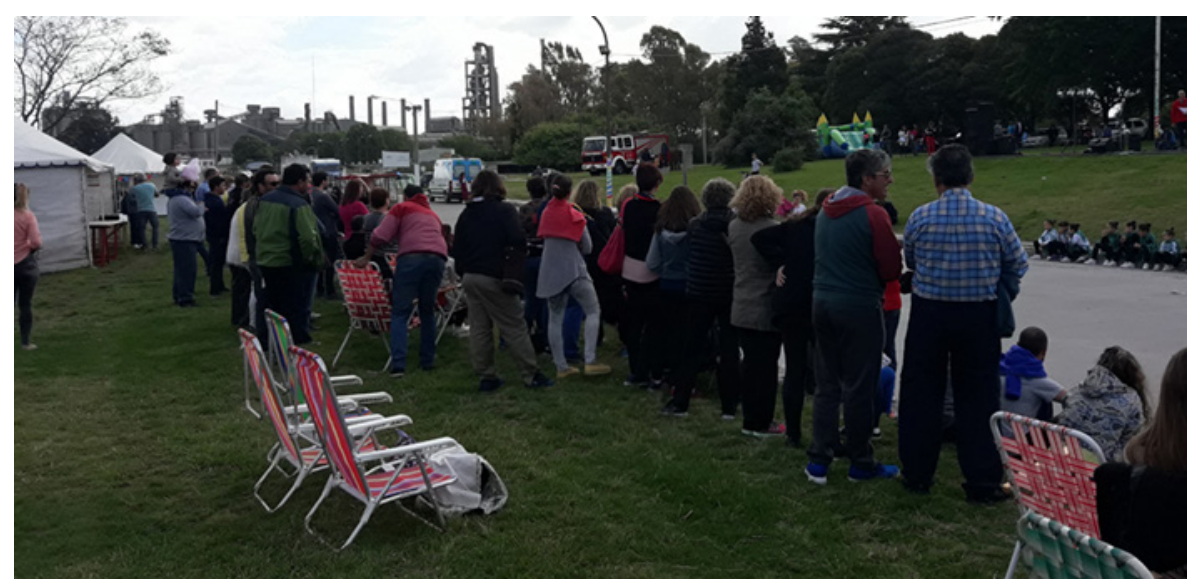


aquel universo cultural local poblado de prácticas y representaciones en la vida cotidiana que da sentido a esta praxis femenina de la limpieza consistente en aprender a limpiar bien, detectar la mugre, sentirla en el cuerpo y volverse locas en el proceso.

\section{Aprendiendo a limpiar}

Marcel Mauss (1979) definió las técnicas del cuerpo como actos eficaces tradicionales que requieren de un adiestramiento transmitido socialmente por imposición o imitación. Estos hábitos hacen uso del cuerpo, o de una parte de él, como una especie de herramienta con la cual ejecutar ciertos procedimientos con habilidad. En Villa Caliza existe un gran número de prácticas de limpieza que las mujeres aprenden en su socialización doméstica. Las tareas concretas que me fueron enumeradas implican un ordenamiento temporal de diferentes actos que podrían clasificarse en: diarios, semanales, mensuales y anuales/estacionales. En ellos, las mujeres comprometen su cuerpo y manipulan una serie de objetos en espacios domésticos. Entre las tareas diarias se cuentan hacer mandados, cocinar, lavar la ropa, barrer, ventilar, hacer la cama, doblar y guardar la ropa limpia. Entre las semanales: ventilar la casa, planchar, lavar pisos, cambiar sábanas, limpiar vidrios, baldear el patio y/o la entrada a la casa, repasar muebles, limpiar el baño. Los actos mensuales evocados consisten en dar vuelta los colchones, limpiar las persianas, lavar cortinas, encerar pisos. Por último, de manera anual y/o estacional las mujeres suben y bajan ropa del placard, y la clasifican según sea para regalar o seguir guardando.

¿Cómo aprendieron las mujeres a hacer estas tareas? El trabajo de campo indica que tanto la imposición como la imitación forman parte de ese aprendizaje. De acuerdo con Mauss, "el niño imita los actos que han resultado certeros y que ha visto realizar con éxito por las personas en quien tiene confianza y que tienen una autoridad sobre él” (Mauss, 1979, p. 340). Las mujeres cuentan que desde pequeñas ayudaban a su madre, abuela, tía o hermana mayor con las cosas de la casa. Estos ejercicios de ayuda (a veces forzados, a veces voluntarios) pautaron su aprendizaje. Esto indica que las aprendizas de loca de la limpieza suelen adquirir sus conocimientos de otra mujer, de más edad, a la que identifican como una loca de la limpieza impecable, es decir, una experta en pulcritud, a la que las une alguna relación de parentesco. La limpieza y el orden son valores positivos que todas las mujeres de Villa Caliza reivindican orgullosamente. Hay dichos populares, como "Limpiar por donde mira la suegra", que señalan que la mirada de los otros sobre la calidad de la propia técnica es prescripta culturalmente. Recordemos que Mauss llama técnica

a la acción que es efectiva y tradicional [...] [y que] el cuerpo es el primer y más natural instrumento del hombre. $\mathrm{O}$, de forma más precisa, sin hablar de instrumentos, el primer y más natural objeto técnico del hombre, yal mismo tiempo su primer medio técnico. (Mauss 1979, p. 391)

Convertirse en una experta de la limpieza implica un desarrollo perceptual del objeto técnico que es el propio cuerpo.

En las historias de estas mujeres, la educación de la percepción en la detección de la mugre es un aspecto de la adquisición de la técnica que aparece en sus vidas cotidianas como algo natural, que nacés sabiendo. Sin embargo, las siguientes escenas señalan un adiestramiento sistemático durante la niñez y la adolescencia en la representación práctica de lo limpio y lo sucio, que implica la aceptación de arbitrariedades que se convierten en principios encarnados de la práctica. El énfasis etnográfico en las relaciones madre-hija con que paso a describirlas se debe a su alta recurrencia en el campo. Esto no implica que el proceso de aprendizaje de las técnicas de limpieza no pueda 
desarrollarse en el contexto de otras relaciones. De hecho, existen otros vínculos de parentesco entre una mujer mayor que exhibe atributos de mujer limpita y una niña o adolescente que aún no lo es, en los que se puede producir este aprendizaje, tales como, el de tía-sobrina, madrina-ahijada, hermana mayor-hermana menor, cuñada-cuñada.

Lo que distingue a una neófita de una loca de la limpieza consagrada es la capacidad de esta de darse cuenta de si algo está sucio. Ese algo son tanto partes de la casa como objetos que se encuentran en ella, tales como prendas de vestir, pisos, muebles, baños, etcétera. Para alcanzar su consagración como experta en limpieza, la neófita primero ha de aprender que ella no posee esa capacidad. Esto se produce a partir de la acusación, de parte de la experta, de la ausencia de destreza en la neófita, cuyo principal indicador es el de no darse cuenta de la mugre que hay en la casa o de lo mugriento que está algo en particular.

Los repertorios con que se practica este comportamiento son diversos: van desde la ausencia de palabras durante las acciones hasta los insultos explícitos. Muchos de ellos son descriptos desde la perspectiva nativa de la neófita como molestos "retos que recibe de la hincha e histérica de mi mamá", a la que una de ellas designa como "la hinchapelotas" (Entrevista personal, Jesica, 16, estudiante de nivel secundario, hija de Marcela, 36, diciembre 2016). Para evitar esos retos de las madres, las hijas cuentan que tratan de "hacer las cosas de la casa" como la madre, de modo de evitar que "se enoje y empiece a los gritos" (Entrevista personal, Antonella, 17, estudiante de nivel secundario, hija de Susana, 50, diciembre 2016). Las madres por su parte expresan molestia respecto a las hijas: "se la pasan papando moscas, no les importa cuidar nada, tienen todo hecho un lío, nunca te agarran un trapo para limpiar, están en la edad del pavo" (Entrevista personal, Susana, 50, ama de casa, septiembre 2016).

Paradójicamente, al preguntarles a las madres cómo enseñan a las hijas a limpiar, enseguida indican con su cuerpo frustración y contrariedad: mueven de lado a lado la cabeza como diciendo no se les puede enseñar. Una hasta me dijo: "mi hija siempre fue tan pero tan inútil con las cosas de la casa, que me parece que tiene un problema mental, le tenés que andar explicando todo" (Registro de campo, Mónica, 53, ama de casa, mayo 2014). Desde el punto de vista de la experta, la mejor aprendiza es aquella que aprende por mímesis, sin molestarla con preguntas o consultas. Las hijas, por su parte, dicen que no les gusta que su madre les enseñe a limpiar porque "se enojan y terminamos peleadas" (Entrevista personal, Luisina, 14, estudiante de nivel secundario, hija de Gabriela, 40, enero 2017) o "porque no saben explicar" (Entrevista personal, Antonella, 17, estudiante de nivel secundario, hija de Susana, 50, enero 2017) o "porque no tienen tiempo con todas las cosas que tienen que hacer" (Entrevista personal, Jesica, 16, estudiante de nivel secundario, hija de Mónica, 53, enero 2017).

La perspectiva con que las hijas hablan de su proceso de aprendizaje en la detección de la mugre indica la presencia de brusquedad: gritos, ausencia de instrucciones claras y violencia física en las interacciones. Este elemento es muy recurrente en los testimonios de las mujeres mayores de 50 años que recuerdan cómo ellas aprendieron a limpiar. Cristina, un ama de casa de 60 años, por ejemplo, cuenta que ella se "hizo limpita a los golpes, mi vieja era brava, nos tenía impecables a mi hermano y a mí, pero nos daba unas biabas" ${ }^{19}$ (Registro de campo, Cristina, 60, julio 2015). Juliana, una de sus hijas, describe la falta de habilidad de su madre para hacerse entender con palabras contando que una vez que llegó a la casa después de la clase de gimnasia del colegio, su madre

estaba a los gritos, yo no entendía nada, me decía que me iba a pegar un bollo, no entendía qué era lo que había pasado. Y era que ime había olvidado de bajar la ropa del cordel! ¡Un escándalo hizo la histérica! (Entrevista personal, Juliana, 35, empleada de comercio, octubre 2016). 
La madre loca es un tópico frecuente de conversación entre las hijas de la villa obrera. Suele incluir anécdotas como la descripta, en las que a la madre le da un ataque de histeria porque la hija falla al intentar realizar alguna tarea doméstica.

Las madres, por su parte, suelen explicar que no tienen tiempo "de andar diciéndole todo" a la hija, que ésta se "tiene que dar cuenta sola, que ya es grande" (Entrevista personal, Mónica, 53, ama de casa, mayo 2015). Incluso me confiesan que les molesta tener a la hija cerca cuando ellas limpian, mirándolas "como una marmota, con todas las cosas que hay que hacer, yo estoy todo el día yendo y viniendo, no tengo tiempo de ponerme a explicarle" (Registro de campo, Marta, 45, ama de casa, octubre 2016). Al decirme cosas como esta, expresan en su cuerpo inquieto, su voz apresurada y sus gestos bruscos una evidente molestia corporal. Así, la hija aprende que tiene que mover su cuerpo incluso con anterioridad al desarrollo de la destreza técnica específica (limpiar pisos, platos, vidrios), pues lo primero que la experta transmite es que las tareas son realizadas con inquietud.

El análisis de los componentes de los "repertorios de experiencias negativas y de compulsiones" (Csordas, 2010, p. 92) a limpiar frenéticamente permite objetivar la predisposición inconsciente a encontrar suciedad. A continuación, describo sintéticamente tres de las principales configuraciones culturales registradas en campo con que se produce la transmisión de la técnica: el enchastre, lo lambeteado y los lamparones.

\section{El enchastre}

El entrenamiento visual en la limpieza implica identificar tanto la mugre que se ve como la que no se ve. Tener los platos en la cocina y los pisos sucios son dos cosas que ninguna loca de la limpieza tolera, pues se trata de dos contundentes indicadores visuales de suciedad. "Una entra a una cocina y enseguida se ve si hay mugre, por eso no me gusta dejar los platos para lavar después, los lavo enseguida después de comer" (Registro de campo, Marta, 45, ama de casa, junio 2016). La educación visual en la limpieza implica no solo lavar, sino estar atenta a no producir nueva suciedad en el mismo proceso, lo cual es nativamente sintetizado en la expresión no dejar enchastre. En varias conversaciones con madres e hijas que mantuve tanto en situación de entrevista como en instancias de observación de su cotidianeidad, las madres se quejaban de que aun cuando las hijas las ayudaban con las cosas de la casa, dejaban todo hecho un enchastre, sobre todo en el espacio de la cocina, donde salpican mucho. Esto señala instancias en la distinción limpio-sucio y ordenado-desordenado, que son ambiguas, pues implican que, si bien los utensilios con los que se ha realizado la cocción de los alimentos y su ingesta han sido aseados, el proceso mismo de limpieza ha producido nuevas manchas, que paradójicamente no son de suciedad. Hacer enchastre al mismo tiempo que se limpia es una de las principales prácticas por las que se va poco a poco aprehendiendo el principio de la locura de la limpieza, pues el enchastre no coincide con lo sucio, pero tampoco con lo limpio.

Este otro intercambio entre una adolescente de 13 años y su madre de 40, también expresa la tensión y contradicción con que se transmite el carácter interminable de la limpieza, pues al limpiar algo, involuntariamente se está ensuciando otra cosa. Nos encontramos luego del almuerzo en el comedor las tres; el padre se ha ido a dormir la siesta. La hija comienza a levantar la mesa y se predispone a lavar los platos. La madre, mientras tanto, mira televisión. La hija en la cocina, abre la canilla y deja correr el agua:

Cuchame, si lavás los platos no me chorreés el piso que lo lavé ayer, a ver si dura un poco... si no, dejá, no laves nada - dice la madre con tono seco e imperativo. Yo no chorreo, y aparte es agua con detergente, si se chorrea ¿qué? -le responde la hija con tono impertinente. 
¡Mancha el piso! - le responde la madre elevando la voz.

¡Pero no es agua sucia, loca! ¡Es agua con detergente! —continúa la hija elevando la impertinencia y el tono de voz.

Pero el piso se chorrea, vos lo pisás, y como estás papando moscas, no te das cuenta y llevás el agua para todos lados, después viene tu hermano, medio tarambana también, y sigue haciendo enchastre y se mancha todo y después viene la tarada (se autoseñala) y tiene que pasar el trapo de nuevo. Dejá que lavo yo los platos - explica la madre bajando el tono y elevando la autoridad. (Registro de campo, casa de Ana, 40, ama de casa y Natalia, 13, estudiante de nivel secundario, marzo de 2016)

\section{Te quedó todo lambeteado}

Una de las prácticas más importantes por las que la hija aprende a limpiar es el acto de lavar el piso. Este tipo de limpieza es una de las tareas que divide a las mujeres: la mitad dice detestarla, la otra mitad expresa preferirla a lavar el baño o a cocinar. Se trata de una actividad en la que todo el cuerpo se compromete. Implica estrujar, deslizar, agacharse, frotar, utilizar los músculos de las piernas, torcer la cintura, tener fuerza en las manos. No hay mujer en Villa Caliza que no haya tenido que limpiar pisos alguna vez y haya experimentado la consistencia viscosa del trapo de piso en el balde, el agua con desodorante que se va ensuciando y se va poniendo color chocolate (señal de que había mucha mugre y se la ha limpiado bien), el esfuerzo sobre la cintura al inclinarse para pasar el trapo en lugares incómodos (debajo o detrás de camas, mesas escritorios, sillones, bidets e inodoros), la agitación de las que están más excedidas de peso y frotan con esmero una superficie extensa, haciendo uno de los pocos esfuerzos cardíacos de la semana, la satisfacción de que quede impecable y lleguen visitas pronto mientras aún se siente el perfume del desodorante en el ambiente, el placer de andar descalza por un suelo bien limpio que no te deja las patas sucias, la impotencia por el marido que llega de la cantera dos horas más tarde con los botines llenos de polvo, el bebé que vomita y el hijo que se olvida de limpiarse las zapatillas antes de entrar.

Al limpiar el piso, la mujer aprende no solo a quitar el polvo que los trabajadores arrastran de sus espacios productivos hacia sus hogares, sino también a hacerlo sin dejar lamparones. Este aspecto del aprendizaje se me hizo patente al participar de un intercambio entre una madre (45) y su hija (15), mientras tomábamos mate y yo les preguntaba cómo se organizaban con la limpieza de la casa. La madre se quedó pensando y mirando fijamente al piso como escrutándolo. Luego hizo un gesto como diciendo "mal hecho" y le preguntó a la hija: “¿Con qué lavaste el piso? Mirá lo lambeteado que te quedó! Todo lleno de lamparones!" (Registro de campo, Silvina, 45, ama de casa y Sofía, 15, estudiante de nivel secundario, abril 2015).

La hija y yo miramos hacia el mismo lugar. El piso a mí me pareció impecable. La hija contestó con tono de hastío, como si ya hubiera oído esto antes, "Y... metí un trapo de piso en un balde con Pinolux y agua... Mucho misterio no hay tampoco". El resentimiento en la voz de la hija es evidente. La madre le responde con un seco tono de

20. Tanto Pinolux como Gloucot son nombres comerciales de limpiadores de pisos. experta: "Ah ¡Con razón! Tenés que usar Gloucot ${ }^{20}$ y no enjuagarlo para que te quede brilloso y sin lamparones" (Registro de campo, Silvina, 45, ama de casa y Sofía, 15, estudiante de nivel secundario, abril 2015).

Este breve intercambio permite identificar dos aspectos importantes del aprendizaje de la adolescente. Por un lado, que ella no conoce ni los productos adecuados ni los procedimientos correctos con los cuales ejecutar la tarea. Por otro lado, que el brillo es tan importante como quitar la mugre. Y, sobre todo, que aun cuando el piso esté limpio, puede exhibir "manchas invisibles" que solo el ojo de una experta entrenada loca de la limpieza es capaz de detectar. Lo lambeteado es una categoría nativa que expresa 
justamente la presencia de manchas — que no son de suciedad-que comprometen el resplandor uniforme de la superficie fregada.

De manera concomitante, el adiestramiento en la percepción olfativa de la limpieza es algo que se aprende lavando pisos. Una de las mujeres me lo sintetizó del siguiente modo: "El olor a limpito de una casa sale del piso. Por más que pongas esas cosas aromáticas que están de moda ahora, si no pasás el trapo todos los días, no hay rico olor en una casa" (Entrevista, Susana, 50, ama de casa, noviembre 2016). El olor a limpio, un objetivo de gran importancia para estas mujeres, tal como se aprecia en la publicidad de los años cuarenta que se muestra en la Imagen 3, se consigue con productos de limpieza que ellas van variando con la intención de conseguir la mejor relación precio-capacidad de dejar brillo y perfume a limpio. Al conversar sobre los productos que usan y cuáles les gustan más, las mujeres suelen comparar y demostrar preferencias. Estas se construyen sobre la base de la valoración de productos, por cuya utilización ellas mismas, y su técnica, son asimismo evaluadas y distinguidas en dos grupos. Por un lado, están quienes conservan la tradición de usar los mismos con los que ellas aprendieron a limpiar, como Marta, que suele decir: "Yo sé que es medio antiguo pero el Puloil ${ }^{21}$ no te lo cambio por nada, te deja la bañera impecable" (Registro de campo, Marta, 45, ama de casa, junio 2016). En cambio, hay otras que demuestran estar al día con la oferta de productos de limpieza en el mercado, exhibiendo diversidad: "Yo prefiero el CIF para la bañera, y el Mr. Músculo para el resto del baño, te desinfecta todo, es bárbaro. Y para el piso, Gloucot ${ }^{22}$, que no te lo deja lambeteado" (Entrevista personal, Patricia, 33, ama de casa, mayo 2015).

Tales conversaciones están, sin duda, influenciadas por la enorme cantidad de horas de televisión en las que los productos de limpieza son publicitados. Desde mediados del siglo $\mathrm{xx}$, los especialistas en marketing dirigen sus mensajes comerciales a mujeres como Marta, Marcela, Susana, Gabriela, Patricia, Jesica, Antonella, Luisina, Lorena, Mariana, Mónica, Cristina, Juliana, Ana, Natalia, Silvina y Sofía. Lo hacen con un contenido de ardua laboriosidad, que se sitúa, primero, en el cuerpo de la mujer exhausto y, luego, en el maravilloso producto que la ayuda a sacar la mugre. Estas publicidades contribuyen a solidificar y reproducir la figura vernacular de la loca de la limpieza, pues el producto de limpieza no viene a reemplazar a la mujer — algo aparentemente no deseado por el ama de casa- sino a hacerla mejor, más industriosa. Incluso, sobrenaturalmente industriosa; como Mr. Músculo, un detergente superconcentrado que adquiere la forma de superhéroe (Imagen 4).

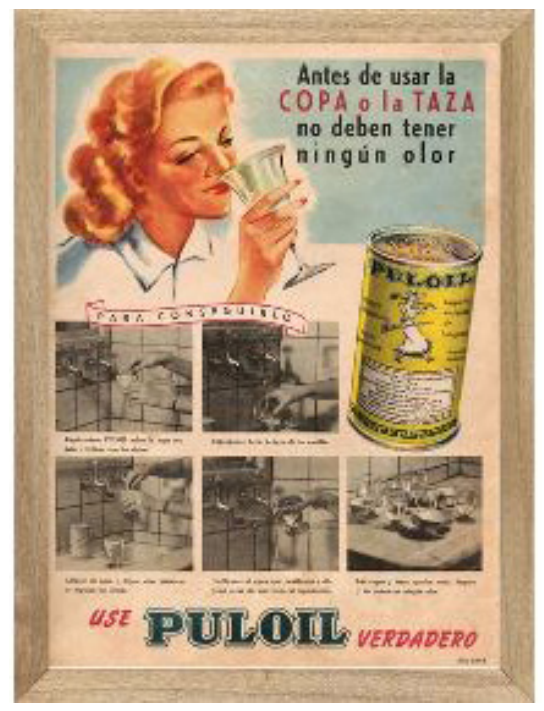

21. Puloil es un polvo limpiador a base de amoníaco, cuya producción ha sido recientemente discontinuada en Argentina.

22. Estas marcas son las que desplazaron a la anterior del mercado nacional. 


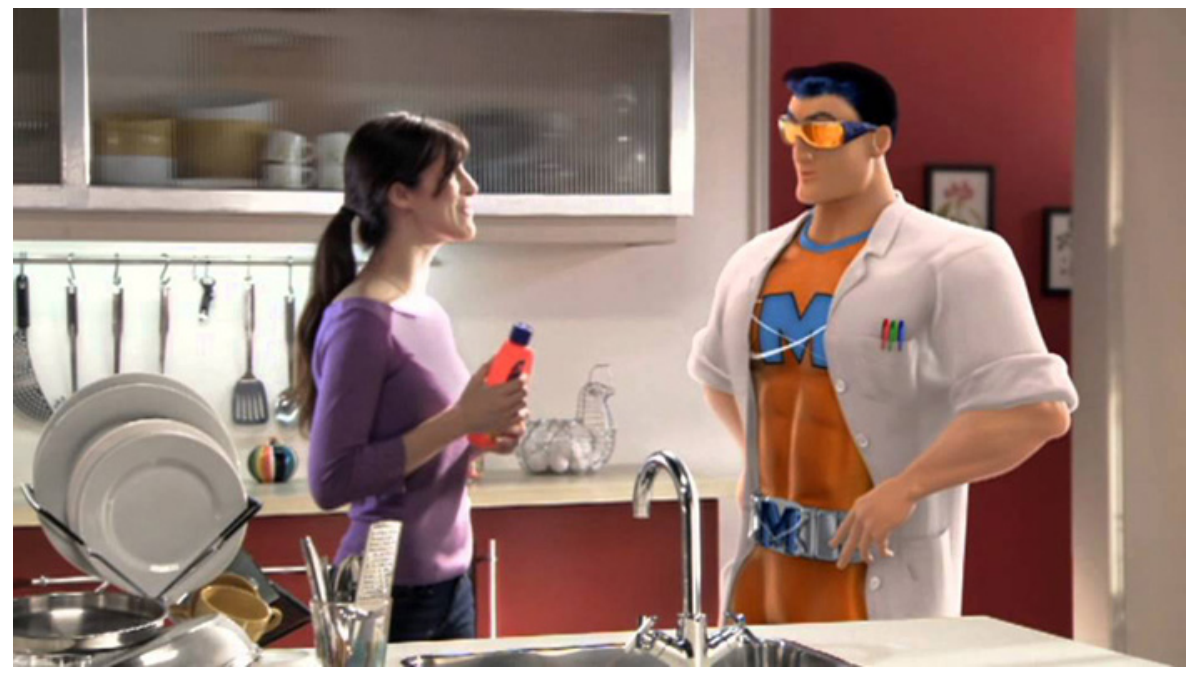

\section{La técnica vuelta hexis industriosa: Sentís la mugre en todo el cuerpo}

La observación prolongada del proceso de entrenamiento de niñas y adolescentes en prácticas de limpieza me condujo a identificar el principio por el que se aprende a "descubrir" la mugre. La combinación de, al menos, dos tipos de percepciones es lo que genera en los actores la experiencia de realizar la tarea con un sentido de praxis. Por ejemplo, para determinar el grado de suciedad que tiene una prenda de ropa, se combinan el olfato y la vista. Un ama de casa de 58 años me explicó así su técnica: "Si vos agarrás una remera y tiene olor a chivo, a calle, está sucia, pero si además tiene los puños y el cuello rozados, está más sucia todavía, la tenés que refregar más" (Entrevista personal, María, 58, ama de casa, enero 2017). Otra manera de producir la relación corporal con la mugre es la de combinar lo táctil con lo visual:

A veces el polvo no se ve tanto, eso pasa mucho con los pisos oscuros. Acá la gente tiene muchos pisos oscuros para que no se note la tierra. Pero una entra a una casa con un piso con mugre y aunque todo sea color gris, y no se vea, uno pisa y ya se da cuenta que ese piso está sucio. Sentís la mugre abajo de los pies, aunque no la veas. (Registro de campo, Silvina, 45, ama de casa, mayo 2016)

Esta descripción sobre el sentido de lo táctil en la detección de la mugre implica la paradoja de que, en realidad, ninguna parte del cuerpo entra de hecho en contacto directo con el polvo, tocándolo, pues la persona lleva los pies calzados. En otras palabras, este testimonio señala que la sensibilidad sensorial táctil en relación con la mugre es tan potente que puede sentirse incluso a través de la suela del calzado. La percepción auditiva también sirve para detectar estas suciedades imperceptibles al ojo. Cómo suena la suela de la zapatilla sobre un suelo sucio es diferente a cómo suena en uno limpio. Así lo sintetiza una de las entrevistadas: "en el suelo sucio no refala tanto, hace un ruido como más seco la zapatilla, también por eso te das cuenta que está sucio el piso" (Registro de campo, Ana, 40, ama de casa, marzo 2016).

La educación perceptual (táctil, visual y olfativa) en la limpieza sedimenta disposiciones que funcionan como marcos de interpretación del actor en su contexto. Estas disposiciones constituyen la hexis corporal de la loca de la limpieza. Mi argumento es que la conversión de niña a loca de la limpieza se caracteriza por volver inconsciente la predisposición a limpiar y esto se produce haciendo que sienta la mugre en su cuerpo. Así, su cuerpo inquieto, dinámico, hábil y atento - en una palabra: industrioso- se ocupa casi inconscientemente todo el tiempo de encontrar y tratar la suciedad. 
El comportamiento mimético copia lo que ve. Tal es el modo en que la técnica en parte se adquiere: se ve a la madre barrer, estrujar el trapo de piso, pasarlo con el palo y el secador, correr las sillas, y se imita cada uno de sus movimientos en la ejecución. Con ver, entonces bastaría para aprender a limpiar. Sin embargo, mi trabajo de campo señala que ese no es el caso, ya que, además de técnica, las expertas transmiten a las neófitas valores asociados a cómo poner el cuerpo, cómo sentirse y cómo moverse. Los actores no se comportan como receptáculos pasivos de reproducir intereses que le son ajenos. Si ese fuera el caso, ¿por qué las mujeres pasan tanto tiempo de su vida educándose las unas a las otras en la limpieza? Con copiar bastaría para lograr la supervivencia de la técnica. La cuestión reside en que, además de imitar, es preciso encarnar.

Podría afirmarse, por tanto, que no solo se transmite la técnica de la limpieza (reproducción), sino también un mecanismo por el que las mujeres que la ejecutan sienten que están descubriendo algo (mugre), que les da la oportunidad de poner en práctica sus propios conocimientos (producción) para eliminarla (limpieza). Es necesaria esta dimensión vivencial de descubrimiento para que los actores se embarquen en la diaria repetición de la ejecución de actos de limpieza, como una praxis (perspectiva nativa) más que como una práctica (perspectiva analítica).

Es la capacidad de descubrir la mugre, sintiéndola, lo que marca su estatus de experta en la práctica y lo que también da nacimiento a la loca de la limpieza como producción cultural. Cuando la neófita siente la mugre en el cuerpo, se produce la conversión en hábito de esa fuerza externa que le fuera inculcada de pequeña para disponerla a limpiar, ordenar, guardar, refregar. Así me lo explican de diferente manera dos mujeres adultas convertidas ya en locas de la limpieza:

Yo antes cuando era chica pensaba que mi vieja era repesada, se la pasaba todo el día limpiando. Pero ahora, más de grande, es como que estoy igualita a ella. Y me da una bronca... Pero es como que no me doy cuenta. Por ahí estoy sentada mirando televisión a la tarde, tomando mate, tranquila, y miro los vidrios y los veo sucios y enseguida agarro un trapo y me pongo a lavarlos ¡No me puedo quedar quieta! Es más fuerte que yo. Mi hermana el otro día me dijo que no viene más a visitarme. Dice que nunca me quedo sentada, que cuando viene me pongo a hacer algo siempre. Pero es que si quedaron los platos del mediodía ¡No los puedo dejar ahí sucios! Me pongo a lavarlos. Es más fuerte que yo (Entrevista personal, Marcela, 36, dos hijos, ama de casa, noviembre 2014).

Yo no sé por qué se me da por ponerme a limpiar cuando estoynerviosa. O tengo que estudiar. Es como que cuando más tengo que poner la cola en la silla para estudiar, menos quieta me puedo tener. ¡No me puedo quedar sentada! Miro el piso, largo las fotocopias, agarro la escoba y me pongo a barrer. O refriego el baño (Entrevista personal, María, 31, un hijo, cursando estudios universitarios, febrero 2017).

La alusión a no poder quedarse quieta que expresan Marcela y María condensa el sentido cultural de lo que llamo la técnica industriosa de la limpieza. El carácter industrioso consiste en realizar la tarea exhibiendo esfuerzo y dedicación, agregándole de esta manera un valor extra a la técnica, en la que el propio cuerpo es tomado por herramienta. La predisposición adquirida a estar nerviosa e inquieta, con el cuerpo constantemente en movimiento, resulta una herramienta eficiente para tener la casa limpia, pues implica un estado de alerta constante respecto de la detección de la mugre. El sentido industrioso de la limpieza se encarna culturalmente en la predisposición a limpiar. Solo esta ejecución parece calmar la inquietud que ellas dicen tener en el cuerpo y que, simultáneamente, obstaculiza la incorporación de disposiciones corporales que implican quietud corporal, pues los actores representan negativamente ese otro hábito como estar sin hacer nada. La locura aparece aquí asociada a esa fuerza exterior que 
domina a la mujer y que esta reconoce como más fuerte que ella, condicionándola para que no pueda dejar de limpiar, aún cuando aparentemente no está obligada a hacerlo. Resulta evidente, además, la tensión entre la disposición adquirida y otros propósitos circunstanciales como estudiar y recibir cortésmente visitas.

\section{Conclusiones}

El epígrafe que encabeza este artículo hace alusión a cuán ardua resulta la tarea de mantener limpio y cálido el hogar. El malestar que vivencian las mujeres al realizar las tareas domésticas de reproducción sugiere que su constitución no es solo local, ya que las sensaciones puestas en la voz imaginaria de personajes de ficción situados en Dakota del Norte en Estados Unidos como narra Erdrich (2016), bien podrían expresar también las de mujeres que en el centro de la provincia de Buenos Aires, Argentina, dedican las horas de sus días a la interminable faena de quitar el polvo de cemento de sus casas y aceras, proceso en el cual se convierten en locas de la limpieza.

El estudio realizado en contextos domésticos de Villa Caliza señala que las mujeres instruyen y son instruidas en una educación somático-perceptual en técnicas del cuerpo que las adiestran industriosamente en la "buena" limpieza. El proceso de conversión de neófita a experta en este tipo de trabajos resulta socialmente exitoso cuando la mujer adiestrada en detectar la mugre encarna la disposición adquirida.

El concepto de técnica corporal permitió identificar el proceso social por el que la destreza es miméticamente transmitida. El concepto bourdiano de hexis corporal contribuyó al entendimiento del sentido de praxis con que la limpieza es vivida por las mujeres. La combinación de sensibilidades perceptivas (olfativa, visual, táctil) demostró ser un elemento clave en el embodiment de la disposición. Esta "educación física doméstica" tiene un doble propósito: entrena la atención (corporal) de las mujeres en la mugre y normaliza la adscripción a la figura vernacular de la loca de la limpieza como proceso relacional de identificación y/u oposición.

Resulta fundamental para la comprensión antropológica del fenómeno de la locura de la limpieza la imbricación entre la dimensión corporal - la inquietud y la molestiay la simbólico-identitaria - el malestar y la locura. Las representaciones nativas del enchastre, los lamparones y el lambeteado contribuyen a introyectar el principio de que una misma acción ejecutada para limpiar puede generar efectos indeseados que comprometen la calidad de la técnica aprendida. Sobre esta contradicción se erige el sentido de praxis con que se realizan las tareas cotidianas de limpieza que refuerzan la tensión inscripta en la hexis corporal.

A partir de estos hallazgos, podría preguntarse: ¿por qué no existen nosologías oficiales profesionales en las que se dé tratamiento a la locura de la limpieza tal como sucede con otros malestares que son profesionalmente categorizados como trastornos de ansiedad, depresión, etc.? ¿Por qué no se diagnostica oficialmente la locura de la limpieza como un trastorno? ¿Por qué esta locura solo es enunciada vernacularmente en la perspectiva de quienes viven cotidianamente el malestar pero no por los profesionales del sufrimiento (psicólogos, psicoanalistas, psiquiatras)?

La respuesta parece hallarse en el sistema social en el que esta conducta es interpretada menos como un "problema" y más como el modo "en que son las cosas". El grupo social de las locas de la limpieza de Villa Caliza se conforma de mujeres en edad productiva que son imprescindibles para el sistema productivo en el que se insertan. En el marco de la contradicción estructural entre capital y trabajo en que se organiza localmente el capitalismo industrial, las amas de casa producen la reproducción de la fuerza de 
trabajo que a diario fabrica la mercancía cemento. Su experticia e industriosidad en estas tareas productivo-reproductivas es practicada, en sus voces nativas, al costo de un malestar que enuncian como una locura permanente que las extrae de la historia, aunque la polifonía de la villa obrera, cristalizada en la propagación de esta elaboración cultural, las reubique sabiendo siempre dónde van a estar: limpiando como unas locas.

\section{Financiamiento}

Los resultados aquí expuestos han podido realizarse gracias a las siguientes fuentes de financiamiento: una beca doctoral Conicet (2013-2018), desarrollada en el marco del Programa de Estudios de los Procesos Socioculturales y Desarrollo Local en la Región Pampeana (03/F146), en la Universidad Nacional del Centro de la Provincia de Buenos Aires; el proyecto "Imaginarios del sistema de servicios urbanos y procesos de gestión con participación en ciudades de rango medio (2012-2015)" de la Agencia de Promoción Científico Tecnológica del MinCyt (1293), en la misma Universidad, dirigido por el Dr. Ariel Gravano; y una estancia de investigación en el Laboratorio de Etnografía Urbana en la Universidad de Texas, bajo la dirección del Dr. Javier Auyero, en el marco de una beca Fulbright - Ministerio de Educación (2018).

\section{Agradecimiento}

Agradezco la lectura atenta del primer borrador de este manuscrito a Javier Auyero, al grupo de becarios doctorales y postdoctorales del CIS-IDES y muy, especialmente, a Ariel Gravano y a mis compañero/as del grupo “Antropología de Ciudades Medias”, en la Facultad de Ciencias Sociales de Olavarría, por brindarme un entusiasmo sostenido en la ardua tarea epistemológica del extrañamiento.

\section{Sobre la autora}

Bárbara Galarza es doctora de la Universidad de Buenos Aires, área Antropología, y profesora adjunta a cargo de Antropología Urbana en la Licenciatura en Antropología Social de la Universidad Nacional del Centro de la Provincia de Buenos Aires. 


\section{Q Referencias bibliográficas}

» Bourdieu, P. (1991). El sentido práctico. Madrid: Taurus.

"Bowman, M. y Valk, U. (2014). Vernacular religion in everyday life. Expressions of belief. Nueva York: Routledge.

» Castel, R. (1997). La metamorfosis de la cuestión social. Una crónica del salario. Buenos Aires: Paidós.

" Csordas, T. (2010). Modos somáticos de atención. En S. Citro (Ed.), Cuerpos plurales. Antropología de y desde los cuerpos (pp. 83-104). Buenos Aires: Biblos.

» Erdrich, L. (2016). El hijo de todos. Madrid: Siruela.

»Federici, S. (2018). El patriarcado del salario. Críticas feministas al marxismo. Buenos Aires: Tinta Limón.

» Fraser, N. (1997). After the family wage: A postindustrial throught experiment. En Justice Interruptus: Critical reflections on the "postsocialist" condition (pp. 41-69). Nueva York: Routledge.

" Geertz, C. (1983). Local knowledge. Further essays in interpretative anthropology. Nueva York: Basic Books.

» Guber, R. (2001). La etnografía. Método, campo y reflexividad. Bogotá: Norma.

» Guber, R. (2013). Villeros o cuando querer no es poder. En A. Gravano (Ed.), Antropología de lo urbano ( $2^{\circ}$ ed.) (pp. 263-310). Buenos Aires: Café de las Ciudades.

»Lambek, M. (1998). Cuerpo y mente en la mente, cuerpo y mente en el cuerpo. Algunas intervenciones antropológicas en una larga conversación. En S. Citro (Ed.), Cuerpos plurales. Antropología de y desde los cuerpos (pp. 105-125). Buenos Aires: Biblos.

» Leite Lopes, S. (1979). Fábrica e vila operária: considerações sobre uma servidão burguesa. En Mudança Social no Nordeste. A reprodução da subordinação (pp. 41-98). Río de Janeiro: Paz e Terra.

» Lins Ribeiro, G. (2011). Descotidianizar. Extrañamiento y conciencia práctica, un ensayo sobre la perspectiva antropológica. En Constructores de otredad. Una introducción a la Antropología Social y Cultural (pp. 240-245). Buenos Aires: Antropofagia.

» Marx, K. (2011 [1867]). El capital: El proceso de producción del capital, T. I, Vol. 2. Buenos Aires: Siglo XXI.

» Mauss, M. (1979) Sociología y antropología. Madrid: Tecnos.

»Neiburg, F. (1989). Fábrica y Villa Obrera: historia social y antropología de los obreros del cemento. Buenos Aires: Centro Editor de América Latina.

» Scheper-Hughes, N. y Lock, M. (1987). The Mindful Body: A Prolegomenon to Future Work in Medical Anthropology. En Medical Anthropology Quarterly (New Series), 1,1, 6-41.

»Sennett, R. (2009). El artesano. Barcelona: Anagrama.

» Tronto, J. (2015 [1952]). Who cares? How to reshape a democratic politics? Nueva York: Cornell University Press.

»Zito, O. y Coumeig, V. (s/f). Villa Caliza. Más de un siglo. Edición de los autores. Disponible en Biblioteca Popular de Villa Caliza. 